University of Wollongong

Research Online

Faculty of Engineering and Information

Faculty of Engineering and Information

Sciences - Papers: Part A

Sciences

$1-1-2015$

Development of magnetoelectric CoFe204 /poly(vinylidene fluoride) microspheres

R Goncalves

Universidade do Minho

P M. Martins

University of Minho

Daniela M. Correia

University of Minho

Vitor Sencadas

University of Wollongong, victors@uow.edu.au

J L. Vilas

Universidad del Pais Vasco(UPV), Bilbao, Spain

See next page for additional authors

Follow this and additional works at: https://ro.uow.edu.au/eispapers

Part of the Engineering Commons, and the Science and Technology Studies Commons

Research Online is the open access institutional repository for the University of Wollongong. For further information contact the UOW Library: research-pubs@uow.edu.au 


\title{
Development of magnetoelectric CoFe204 /poly(vinylidene fluoride) microspheres
}

\author{
Abstract \\ Magnetoelectric microspheres based on piezoelectric poly(vinylidene fluoride) (PVDF) and \\ magnetostrictive $\mathrm{CoFe}_{2} \mathrm{O}_{4}$ (CFO), a novel morphology for polymer-based ME materials, have been \\ developed by an electrospray process. The CFO nanoparticle content in the (3-7 mm diameter) \\ microspheres reaches values up to $27 \mathrm{wt} \%$, despite their concentration in the starting solution reaching \\ values up to $70 \mathrm{wt} \%$. Additionally, the inclusion of magnetostrictive nanoparticles into the polymer \\ spheres has no relevant effect on the piezoelectric b-phase content (z60\%), crystallinity (40\%) and the \\ onset degradation temperature (460-465 C) of the polymer matrix. The multiferroic microspheres show a \\ maximum piezoelectric response $|d 33|$ z $30 \mathrm{pC}$ N1, leading to a magnetoelectric response of $\mathrm{D}|\mathrm{d} 33| \mathrm{z} 5$ \\ pC N1 obtained when a $220 \mathrm{mT}$ DC magnetic field was applied. It is also shown that the interface \\ between CFO nanoparticles and PVDF (from 0 to 55\%) has a strong influence on the ME response of the \\ microspheres. The simplicity and the scalability of the processing method suggest a large application \\ potential of this novel magnetoelectric geometry in areas such as tissue engineering, sensors and \\ actuators. \\ Disciplines \\ Engineering | Science and Technology Studies

\section{Publication Details} \\ Goncalves, R., Martins, P., Correia, D. M., Sencadas, V., Vilas, J. L., Leon, L. M., Botelho, G. \& Lanceros- \\ Méndez, S. (2015). Development of magnetoelectric $\mathrm{CoFe}_{2} \mathrm{O}_{4} /$ poly(vinylidene fluoride) microspheres. \\ RSC Advances: an international journal to further the chemical sciences, 5(45), 35852-35857.

\section{Authors} \\ R Goncalves, P M. Martins, Daniela M. Correia, Vitor Sencadas, J L. Vilas, L M. Leon, Gabriela Botelho, and \\ Senentxu Lanceros-Méndez
}




\title{
ARTICLE
}

Cite this: DOI: 10.1039/xoxxooooox

Received ooth January 2012,

Accepted ooth January 2012

DOI: 10.1039/xoxxooooox

www.rsc.org/

\section{Development of novel magnetoelectric $\mathrm{CoFe} 2 \mathrm{O} 4$ /poly(vinylidene fluoride) microspheres}

\author{
R. Gonçalves ${ }^{\mathrm{a}, \mathrm{b}}$, P. Martins ${ }^{\mathrm{a},{ }^{*}}$, D. M. Correia ${ }^{\mathrm{a}, \mathrm{b}}$, V. Sencadas ${ }^{\mathrm{a}}$, J. L.Vilas ${ }^{\mathrm{c}}$, L. M. \\ León $^{\mathrm{c}, \mathrm{d}}$, G. Botelho ${ }^{\mathrm{b}}, \mathrm{S}$. Lanceros-Méndez ${ }^{\mathrm{a}^{*}}$
}

Magnetoelectric microspheres based on piezoelectric poly(vinylidene fluoride) (PVDF) and magnetrostrictive $\mathrm{CoFe}_{2} \mathrm{O}_{4}$ (CFO), a novel morphology for polymer-based ME material, have been developed by an electrospray process. The CFO nanoparticles content in the (3-7 $\mu \mathrm{m}$ diameter) microspheres reaches values up to $27 \mathrm{wt} . \%$, despite their concentration in the starting solution reaching values up to $70 \mathrm{wt} \%$. Additionally, the inclusion of magnetostrictive nanoparticles into the polymer spheres has no relevant effect on the piezoelectric $\beta$-phase content $(\approx 60 \%)$, crystallinity $(40 \%)$ and the onset degradation temperature $\left(460^{\circ}-465^{\circ} \mathrm{C}\right)$ of the polymer matrix. The multiferroic microspeheres show a maximum piezoelectric reponse $|\mathrm{d} 33| \approx 30 \mathrm{pC} . \mathrm{N}^{-1}$, leading to a magnetoelectric response of $\Delta|\mathrm{d} 33| \approx 5 \mathrm{pC} . \mathrm{N}^{-1}$ obtained when a $220 \mathrm{mT}$ DC magnetic field was applied. It is also shown that the interface between CFO nanoparticles and PVDF (from 0 to 55\%) has a strong influence on the ME response of the microspheres. The simplicity and the scalability of the processing method suggest a large application potential of this novel magnetoelectric geometry in areas such as tissue engineering, sensors and actuators.

\section{Introduction}

The magnetoelectric (ME) effect, defined as the variation of the electric polarization in response to an applied magnetic field or the variation of the magnetization under an applied electrical field is a scientifically interesting and technological useful phenomenon with an increasing range of applications in areas such as computer memories, smart sensors, actuators, high frequency microelectronic devices and biomedical materials ${ }^{1-4}$. The ME effect can occur on single-phase materials or in composites due to the combination of magnetostrictive and piezoelectric responses ${ }^{5-8}$. Single-phase ME materials, typically show very low ME coupling exhibited at low temperatures, hindering their implementation into technological applications $1,7,9$. Multiferroic composites emerged as an interesting possibility for device applications as in those composites, consisting on the combination of magnetostrictive and piezoelectric phases, the ME effect is the result of a product property, i.e., the mechanical deformation induced by a magnetic field due to the magnetostriction of one of the phases, results in a dielectric polarization variation due to the piezoelectric effect of the other phase, allowing large $\mathrm{ME}$ effects at room temperature ${ }^{2,7,10}$.

$\mathrm{ME}$ composite materials can be ceramic or polymer based. Ceramicbased ME materials exhibit ME coefficients three orders of magnitude higher than polymer-based ME materials, but they are limited by reactions at the interface regions which lead to high dielectric losses, hindering sustainable device applications ${ }^{1}$.

Thus, polymer-based ME materials have attracted increasing interest from the industry since they solve the abovementioned application problems $^{1,}{ }^{11}$. Further, in polymer-based ME materials strain coupling does not deteriorate with operation, as the magnetostrictive material is in direct contact with and completely surrounded by the piezoelectric polymer matrix, they show simple and scalable production methods, a flexible structure without large leakage currents, can be fabricated by conventional low-temperature polymer processing into a variety of forms, such as thin sheets or molded shapes, can exhibit tailored mechanical properties, flexibility, lightweight, versatility, low cost and in biocompatibility ${ }^{1,2}$.

In particular, polymer-based ME spheres composed by magnetostrictive nanoparticles within a piezoelectric polymer matrix, can open new applications areas and solve some drawbacks of the traditional polymer-based structures (nanocomposites, polymer as a binder and laminates) such as agglomeration, irregular distributions and the difficulty to shape in a miniaturized form ${ }^{1,12}$. Polymer-based micro and nanospheres undergo an increasing demand and applicability as biomaterials for cell culture, drug delivery systems, electro-optic and luminescent devices, heterogeneous catalysis and polymer powder impregnation of inorganic fibers in composites ${ }^{13-16}$.

Particularly, low-scale piezoelectric materials such as spheres show strong potentials for improved energy harvesters with higher volume efficiency, nano-sensors and nano-actuators and nano-mats guiding cell distribution ${ }^{17,18}$. The addition of magnetostrictive materials into the piezoelectric spheres allows the use of the resulting composite also as magnetic nano-sensors and actuators, as well as to take advantage of the induced the ME phenomenon ${ }^{7}$.

To our knowledge there are no previous reports on polymer-based ME spheres, that can be an innovative and desired solution for 
applications in which multifunctional active response is needed (either magnetic to electrical or mechanical to electrical responses, due to the ME and piezoelectric effects) such as in non-invasive control of cell growth and differentiation, active drug release and tissue stimulation ${ }^{14,16}$.

For the formation of polymer microspheres several methods have been used such as gas atomization, microdroplet, dispersion polymerization, evaporation and precipitation, emulsion polymerization ${ }^{13}$, oil in water $(\mathrm{O} / \mathrm{W})$ or water in oil $(\mathrm{W} / \mathrm{O})$ emulsions, coacervation and spray drying, among others ${ }^{19}$. Unlike previous methods that require high-energy input devices like sonicators and/or high-cost devices such as high-pressure homogenisers, electrospray technique is a straightforward and versatile technique featuring advantages like ambient condition and single-step processing, high reproducibility, high yield and economical set-up ${ }^{15,20,21}$.

In this work the development of novel $\mathrm{CoFe}_{2} \mathrm{O}_{4}$ (CFO)/polyvinylidene fluoride (PVDF) multiferroic spheres is reported, with large potential applications in the biomedical, sensing, actuation, catalysis and energy fields ${ }^{13-15}$.

PVDF, a piezoelectric polymer with five possible distinct crystalline phases named as $\alpha, \beta$-phase, $\gamma, \delta$ and $\varepsilon$, was selected as the piezoelectric component due to its biocompatibility, high piezoelectric response, large chemical and radiation resistance, easy shaping and low cost ${ }^{11,22-24}$. CFO nanoparticles were selected as the magnetostrictive phase due to their chemical stability, mechanical hardness, wear resistance, ease of synthesis, large magnetostriction, high Curie temperature, low cost and simple processability 25, 26 . Additionally, the high magneto-crystalline anisotropy of the CFO nanoparticles is very interesting and useful for their use in medical applications ${ }^{27}$.

\section{Experimental}

\section{Materials and methods}

Poly(vinylidene fluoride), PVDF, reference Solef 1010, was acquired from Solvay. Analytical grade tetrahydrofuran (THF) and $\mathrm{N}, \mathrm{N}$-dimethyl formamide (DMF) were purchased from Panreac and Merck, respectively. $\mathrm{CoFe}_{2} \mathrm{O}_{4}, \mathrm{CFO}$, nanoparticles with 35-55 $\mathrm{nm}$ particle size, was purchased from Nanoamor. Laboratory grade Triton X-100 was purchased from Sigma-Aldrich.

\section{Composite preparation}

The CFO nanoparticles were dispersed in DMF solvent and Triton $\mathrm{X}-100$ in an ultrasound bath during $4 \mathrm{~h}$ to ensure good dispersion and avoid nanoparticle agglomeration. Then, PVDF and THF were added and placed in a Teflon mechanical stirrer and an ultrasound bath until complete dissolution of the polymer. Composite solutions with CFO contents between 10 weight percentage (wt.\%) and 70 wt.\% were produced.

\section{Electrospray processing}

The composite solution was placed in a commercial plastic syringe fitted with a steel needle with inner diameter of $0.5 \mathrm{~mm}$. Electrospray was conducted by applying $20 \mathrm{kV}$ with a PS/FC30P04 power source from Glassman. A syringe pump (Syringepump) feed the polymer solution into the tip at a $1 \mathrm{~mL} / \mathrm{h}$ rate. The electrosprayed samples were collected on a grounded collecting plate placed at 20 $\mathrm{cm}$ from the needle tip.

\section{Sample characterization}

The morphology of the CFO/PVDF spheres was evaluated by Scanning Electron Microscopy (SEM) (Quanta 650, from FEI) with an accelerating voltage of $5 \mathrm{kV}$. Sphere average diameter and distribution was calculated over approximately 30 microspheres using SEM images (5000 X magnification) and the Image $\mathrm{J}$ software.

The magnetic properties of the multiferroic spheres were evaluated by measuring the magnetization loops $\mathrm{M}(\mathrm{H})$ up to $10 \mathrm{kOe}$ using an Oxford Instruments vibrating sample magnetometer. Fourier Transform Infrared Spectroscopy (FTIR) technique was carried out at room temperature in a Bruker alpha apparatus in ATR mode from 4000 to $400 \mathrm{~cm}^{-1}$ using 24 scans at a resolution of $4 \mathrm{~cm}^{-1}$. Specific bands such as the ones at 766 and $840 \mathrm{~cm}^{-1}$ have been identified to correspond to the $\alpha$ and $\beta$-phase, respectively, allowing the calculation of the polymer phase content after the procedure described in ${ }^{22}$. The $\beta$-phase fraction $(F(\beta))$ can thus be determined by applying equation 1 :

$$
F(\beta)=\frac{A_{\beta}}{\left(\frac{K_{\beta}}{K_{\alpha}}\right) A_{\alpha}+A_{\beta}}
$$

where $F(\beta)$ represents the $\beta$-phase content; $A_{\beta}$ and $A_{\alpha}$ the absorbance at 840 and $766 \mathrm{~cm}^{-1}$, respectively and $K_{\beta}\left(7.7 \times 10^{4} \mathrm{~cm}^{2} \cdot \mathrm{mol}^{-1}\right)$ and $K_{\alpha}\left(6.1 \times 10^{4} \mathrm{~cm}^{2} \cdot \mathrm{mol}^{-1}\right)$ are the absorption coefficients at the respective wavenumber for both phases ${ }^{22}$.

The thermal behaviour of the samples was determined by Differential Scanning Calorimetry (DSC), measurements in a Mettler Toledo 822e apparatus with sample robot and STAR software, using a heating rate of $10{ }^{\circ} \mathrm{C} \cdot \mathrm{min}^{-1}$ under nitrogen purge $\left(50 \mathrm{~mL} \cdot \mathrm{min}^{-1}\right)$; and by ThermoGravimetric Analysis (TGA). For the TGA measurements, samples were transferred to open ceramic crucibles with capacity of $60 \mu \mathrm{L}$ and analysed using a METTLER TGA/SDTA 851 thermobalance operating between $200^{\circ} \mathrm{C}$ and $700^{\circ} \mathrm{C}$. A heating rate of $10 \pm 0.2{ }^{\circ} \mathrm{Cmin}^{-1}$ and nitrogen flow rate of $50 \mathrm{~mL} / \mathrm{min}$ were used.

The crystallinity content $(\mathrm{Xc})$ of the PVDF samples was calculated applying equation $2^{21}$ :

$$
X_{c}=\frac{\Delta H}{x \Delta H_{\alpha}+y \Delta H_{\beta}}
$$

where $\Delta H$ is the melting enthalpy of the sample; $\Delta H_{\alpha}$ and $\Delta H_{\beta}$ are the melting enthalpies of a $100 \%$ crystalline sample in the $\alpha$ and $\beta$ phase and $x$ and $y$ indicate the amount of $\alpha$ and $\beta$ phase present in the sample, respectively. $\Delta H_{\alpha}$ and $\Delta H_{\beta}$ were considered as 93.07 and $103.4 \mathrm{~J}^{-g^{-128}}$.

Form the TGA results, the nanofiller/polymer interface region of the CFO/PVDF spheres was obtained, applying equation $3^{23}$ :

$$
m_{I}=\frac{m(x)_{I O}-m_{I O}}{m_{I O}} \times 100
$$

where $\mathrm{m}_{\mathrm{I} 0}$ is the mass of the pristine polymer at the temperature at which the mass loss rate is maximum and $\mathrm{m}(\mathrm{x})_{\mathrm{IO}}$ is the mass of the composite containing a given wt.\% of nanoparticles that has not degraded at the temperature at which the mass loss rate of the pristine polymer is maximum.

After poling conditions optimization, $30 \mathrm{~min}$ of corona poling at 10 $\mathrm{kV}$ and $120{ }^{\circ} \mathrm{C}$ were applied in a home-made chamber in order to optimize the piezoelectric response of the samples. Then, the piezoelectric response $(\mathrm{d} 33)$ of the samples was analysed with a wide range d33-meter (model 8000, APC Int Ltd).

The ME character of the CFO/PVDF spheres was evaluated by the difference in the piezoelectric response obtained with and without the application of a 220 Oe DC magnetic field $\left(\Delta \mathrm{d}_{33}\right)$. 


\section{Results and discussion}

VSM technique has proved to be a precise technique able to accurately determine the magnetic nanoparticle content on composites $^{29-31}$. Thus, the hysteresis curves shown in Figure 1 were first used to evaluate the efficiency of the particle loading process, i.e. the relation between the content of the CFO nanoparticles within the solution and the concentration in the obtained spheres (Figure 1).

\section{(1)}

$$
\text { a) }
$$

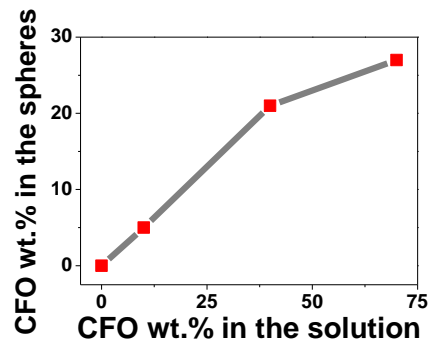

b) the needle hole by agglomeration of nanoparticles, due to the flow funnelling towards the needle. Figure 2 a-e shows representative SEM images of ME CFO/PVDF spheres with 5-27 wt.\% ferrite content.
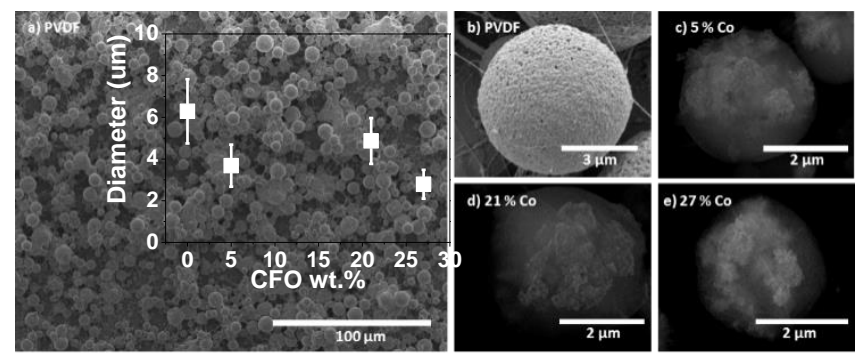

Figure 2. Morphology of PVDF polymer (a and b) and the multiferroic CFO/PVDF microparticles with CFO wt.\% 5 (c), 21 (d) and 27 (e) CFO nanoparticle content.

The low magnification image (Figure 2a) shows a homogeneous production of multiferroic spheres, with good dispersion and spherical shape. Spheres diameters were between 3 and $7 \mu \mathrm{m}$, nearly independently of the CFO filler content. The insertion of the CFO magnetic fillers within the PVDF polymer sphere originates just a slight decrease of the average sphere diameter

CFO/PVDF spheres. (b) Relation between the wt.\% of CFO nanoparticles within the solution and the wt.\% of CFO nanoparticles within the multiferroic spheres, obtained from the hysteresis loops.

Figure 1a reveals the typical ferromagnetic behavior of the CFO/PVDF spheres. For all compositions, the magnetization saturates at $\approx 2 \mathrm{kOe}$. As expected, the magnetization saturation increases with increasing nanoparticle filler content. By comparing the saturation magnetization value of the pure CFO nanoparticles with the ones from Figure 1a it is possible to determine, trough equation 4 , the precise amount of CFO nanoparticles within the multiferroic sphere (Table 1).

\begin{tabular}{l|l|l|l}
\hline \hline $\begin{array}{c}\text { CFO wt\% } \\
\text { in the } \\
\text { solution }\end{array}$ & $\begin{array}{l}\text { Spheres } \\
\text { Saturation } \\
\text { Magnetization } \\
\text { (expected) }\end{array}$ & $\begin{array}{l}\text { Spheres } \\
\text { Saturation } \\
\text { Magnetization } \\
\text { (measured) }\end{array}$ & $\begin{array}{l}\text { Calculated } \\
\text { CFO wt.\% } \\
\text { in spheres }\end{array}$ \\
\hline 10 & 6 & 3.0 & 5 \\
\hline 40 & 24 & 12.8 & 21 \\
\hline 70 & 42 & 16.4 & 27 \\
\hline $100^{*}$ & 60 & 60.0 & 100 \\
\hline \hline
\end{tabular}

*pure powder

$$
\begin{aligned}
& \text { CFO wt. } \%_{\text {Spheres }} \\
& =\frac{\text { Saturation Magnetization }}{\text { Spheres } \times 100} \\
& 60
\end{aligned}
$$

Figure $1 \mathrm{~b}$ and Table 1 show that with 10 wt.\%, 40 wt.\% and 70 wt.\% CFO content within the solution leads to spheres with 5 wt.\%, 21 wt.\% and 27 wt.\% CFO contents, respectively. Thus, the maximum CFO content allowed in the spheres starts to saturate at $\sim 20 \mathrm{wt} . \%$, since an increase of $30 \mathrm{wt} . \%$ in the solution $\mathrm{wt} \%$ content of CFO (from $40 \%$ to $70 \%$ ) leads to just an increase of just $6 \%$ of CFO nanoparticles inside the multiferroic sphere (from $21 \%$ to $27 \%)$.

In this way, the concentrations of $\mathrm{CFO}$ nanoparticles in the electrosprayed spheres is lower than the ones on the composite solutions, in agreement to previous reports ${ }^{32}$ and can be attributed to the higher density of the CFO nanoparticles (when compared to the polymer matrix) that causes the settling of some nanoparticles on the bottom of the syringe during the electrospinning process. Further, some contributions can also come from a partial blockage of
Backscattering images (figures 2c-e) reveal that the CFO nanoparticles are effectively inside (white zones of figures $2 \mathrm{c}-\mathrm{e}$ ) the polymer spheres, wrapped by the polymer matrix (spherical structure of figure $2 b$ ), giving rise to the desired multiferroic polymer composite structure.

Since the presence of the piezoelectric $\beta$ crystalline phase of PVDF is an essential requirement to obtain ME response on PVDF based ME materials ${ }^{1}$, FTIR was used to identify and quantify the $\beta$-phase content of PVDF.

For the pure polymer and the CFO/PVDF microspheres, typical FTIR spectra are presented in Figure $3 a$ and the calculated $F(\beta)$, equation 1, is represented in Figure $3 b$.

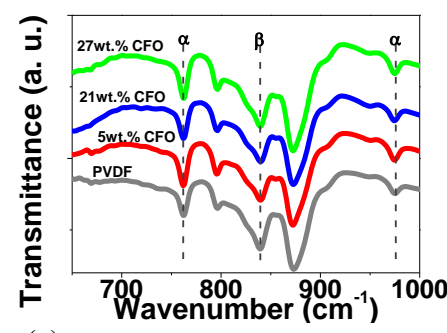

(a)

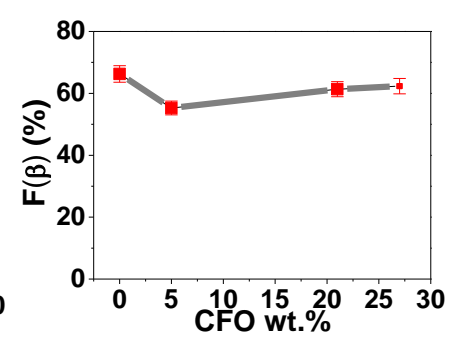

(b)
Figure 3. FTIR spectra of (a) pure PVDF microspheres and CFO/PVDF composites microspheres with 5, 21 and $27 \mathrm{wt} \%$ filler content and (b) variation of $\beta$-phase content as a function of CFO content.

Figure 3a shows that the crystalline phase of the polymer matrix in the microspheres are mainly in the $\beta$-phase and no significant differences between the spectra of the different composite microsphere are detected. All microspheres, pure PVDF and CFO/PVDF composites, show $\beta$-phase contents between 65 and 75\% and that this value is independent of the CFO content. It is to notice that those $\beta$-phase contents are compatible with the maximum piezoelectric response of the polymer, as it has been verified in ${ }^{33}$. In this way, the $\beta$-phase formation is mainly attributed to the low solvent evaporation temperature $\left(\leq 60{ }^{\circ} \mathrm{C}\right)$, which mainly leads to the crystallization of the polymer in this phase ${ }^{15,34}$. Further, electrostatic 
interaction of the filler nanoparticles with the highly polar polymer chains certainly reinforce this effect, as it has been verified in samples prepared after melting, that are nucleated in the $\beta$-phase, whereas the polymer without fillers remain in the $\alpha$-phase ${ }^{15}$.

Figure 4a shows the DSC thermograph of the microspheres of PVDF and CFO/PVDF composites. From the melting endotherm and applying equation 2 , the degree of crystallinity (Xc) was obtained, as represented in Figure 4b.

(a)

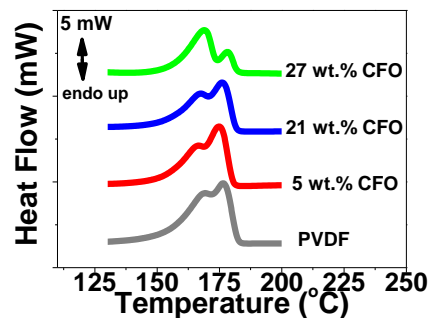

(b)

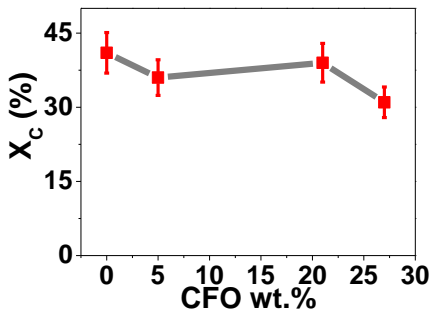

Figure 4. (a) DSC thermographs and (b) degree of crystallinity of the pristine PVDF and the CFO/PVDF composite microspheres.

The DSC thermographs of all samples are characterized by a double endothermic peak, related both to the existence of polymer crystallization in both $\alpha$ and $\beta$ crystalline structures as confirmed by FTIR (Figure 3 ) results ${ }^{35}$ and the presence of the nanofillers. In both cases ill-crystallized region arises with lower melting temperature due to the larger energy of the imperfect structures. The degree of crystallinity values (Figure 4b) are in good agreement with the ones obtained in PVDF processed by similar procedures ${ }^{36}$. Additionally, the overall lower degree of crystallinity is slightly lower when the fillers are present in the polymer matrix, which is attributed to hindered crystallization due to the presence of the fillers, which can act as nucleation centers for crystallization, but also hinder spherulite growth $^{31,35}$.

The interface between magnetostrictive materials and piezoelectric polymers is one of the most sensitive parameters influencing the ME response of the composites. This interface can be determined by the TGA results presented in (Figure 5) ${ }^{23,36}$.

(a)

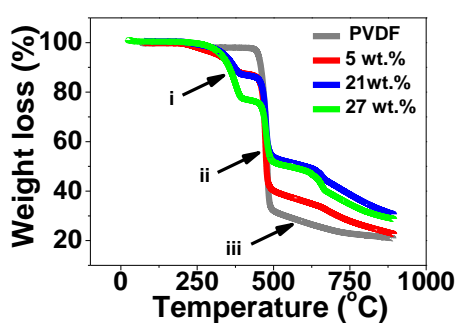

(b)

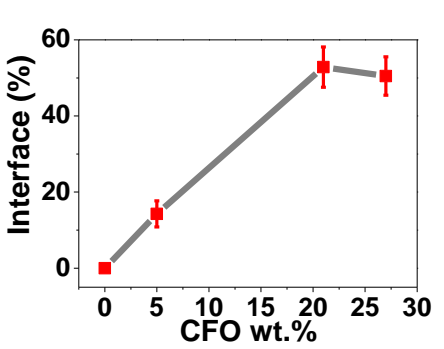

Figure 5. (a) TGA thermographs for the different samples and (b) interface volume between nanoparticles and polymer as a function of CFO nanoparticle concentration.

In all composite spheres samples, with and without CFO nanoparticles, the typical two step thermal degradation, characteristic of PVDF, was observed ${ }^{37}$. The onset temperature, defined as the temperature at which the polymer lost $1 \%$ of its weight, was found to be $\approx 460{ }^{\circ} \mathrm{C}$ for the pure PVDF microspheres, slightly lower than the ones obtained on CFO/PVDF microspheres that was around $\approx 465{ }^{\circ} \mathrm{C}$. This results shows that the addition of the CFO nanoparticles into the PVDF spheres slightly improves the thermal stability of the microspheres. Such effect has already been reported in previous studies ${ }^{23}$ and can be attributed to two factors: (i) the CFO filler in the composite can hinder the formation and escape of volatile by-products during heating and (ii) the thermal motion of

PVDF segments near the CFO surfaces may be restricted because of the physical interlock and electrostatic interaction ${ }^{38}$.

The first degradation step occurs between $\approx 400$ and $\approx 500{ }^{\circ} \mathrm{C}$ (ii), being the polymer maximum degradation temperature not influenced by the CFO content. In this initial degradation step the decomposition mechanism is chain-stripping where carbon-hydrogen and carbon-fluorine scission occurs, the presence of both hydrogen and fluorine radicals leading to the formation of hydrogen fluoride ${ }^{37}$,

The second degradation step occurs between $\approx 500$ and $\approx 850{ }^{\circ} \mathrm{C}$ (iii), and the differences observed in the plots relatively to the pure PVDF spheres sample are to be ascribed to the presence of CFO nanoparticles, as the different phases of PVDF show similar thermal degradation behavior ${ }^{40}$. This second step is a complex degradation process resulting in poly(aromatization). The polyenic sequence formed previously on the first degradation step is unstable and, as a consequence, the macromolecules formed undergo further reactions leading to scission followed by the formation of new aromatic molecules $23,37,41$.

Previously to these typical two thermal degradation steps, an additionally degradation was observed between $\approx 290$ and $\approx 400{ }^{\circ} \mathrm{C}$ (i)resultant from the degradation of the Triton X-100 ${ }^{42}$.

Figure $5 \mathrm{~b}$ shows the mass fraction of the polymer located at the interface as a function of the CFO content, calculated after equation 3 . The interface value increases with increasing ferrite loading as a result of the increased number of particles interacting with the polymer matrix up to a filler content of $\sim 20 \mathrm{wt} . \%$, after this value, increasing $\mathrm{CFO}$ content has a result a small decrease in the CFO/PVDF interface, explained by the fact that a larger filler content can lead to the formation of clusters and agglomerations and therefore a decrease of the overall surface contact area. The highest interface value (55\%) was obtained for the CFO/PVDF spheres with 21 wt. $\%$ ferrite content. This interface value is $\approx 40 \%$ higher than the one reported to CFO/PVDF multiferroic composite films ${ }^{43}$ and will lead to an increased ME coupling due to the larger contact area between the magnetostrictive and piezoelectric phases.

The ME coupling was measured ${ }^{44,45}$ by evaluating the piezoelectric response of the composites without and with an applied magnetic field of $220 \mathrm{mT}$ (Figure 6).

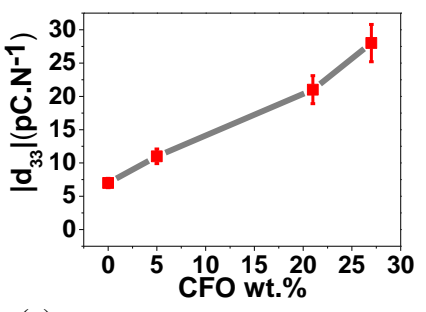

(a)

Figure 6. (a) Modulus of the piezoelectric coefficient $\left|d_{33}\right|$ as a function of CFO wt.\% and (b) $\Delta\left|\mathrm{d}_{33}\right|$ as a function of CFO wt.\%.

Figure 6a represents the variation of the piezoelectric response of the samples (polymer films made out of spheres-Figure 2) as a function of filler content. The presence of the CFO nanoparticles improves the piezoelectric response of composite spheres due to the electrostatic interactions between particles and polymer ${ }^{31,34}$.

Once a $220 \mathrm{mT}$ DC magnetic field was applied with two permanent magnets, at the same time that the piezoelectric response is being measured, an increase in the $\left|\mathrm{d}_{33}\right|$ value is observed in the composite samples but no variation is detected in the pristine polymer samples revealing the ME character of the multiferroic spheres (Figure 2b). Since magnetostrictive CFO induces displacements at the interface between nanoparticles and polymer ${ }^{46}$, with increasing interface 
value, the interaction between the piezoelectric PVDF and the magnetostrictive CFO ferrites will be promoted, explaining the larger increase of the $\Delta\left|\mathrm{d}_{33}\right|$ with increasing nanoparticle content until $\sim 20$ wt.\%. Such interaction will be hindered for higher CFO concentrations, due to the decrease of the previously shown interface area (Figure 5b), leading to a lower ME coupling and a decrease in the $\left|\mathrm{d}_{33}\right|$ variation value.

\section{Conclusions}

Magnetoelectric CFO/PVDF microspheres have been prepared by an electrospray process. The concentrations of $\mathrm{CFO}$ nanoparticles in the microspheres reaches values up to $0-27$ wt.\%, though their concentration in solution reaches values up to $70 \mathrm{wt} . \%$. Spheres diameters were found to be between 3 and $7 \mu \mathrm{m}$, being the size nearly independent of the CFO filler content.

The addition of CFO nanoparticles into the polymeric spheres has almost no effect on the $\beta$-phase content $(\approx 60 \%)$, crystallinity $(40 \%)$ and the onset degradation temperature $\left(460^{\circ}-465^{\circ} \mathrm{C}\right)$ of the polymer matrix.

The interface between CFO nanoparticles and PVDF was found to have a strong influence on the $\mathrm{ME}$ response of the $\mathrm{CFO} / \mathrm{PVDF}$ spheres. Increased interface values (from 0 to $55 \%$ ) had as result and optimized ME response $(\Delta|\mathrm{d} 33|$ from 0 to 5 pC. $\mathrm{N}^{-1}$ ) when a $220 \mathrm{mT}$ DC magnetic field was applied to the CFO/PVDF spheres with 21 wt.\% of ferrite. Thus, the overall properties of the ME microspheres and the simplicity and scalability of the processing method indicates a large potential of the CFO/PVDF multifunctional microspheres for developing advanced applications.

\section{Acknowledgements}

This work is funded by FEDER funds through the "Programa Operacional Factores de Competitividade - COMPETE" and by national funds from FCT - Portuguese Foundation for Science and Technology, in the framework of the strategic project Strategic Project PEST-C/FIS/UI607/2014 and PEstC/QUI/UI0686/2014). Authors would like to thank to J. C. Dias for the TGA measurements. The authors also thank funding from Matepro -Optimizing Materials and Processes", ref. NORTE-07-0124-FEDER-000037", co-funded by the "Programa Operacional Regional do Norte" (ON.2 - O Novo Norte), under the "Quadro de Referência Estratégico Nacional" (QREN), through the "Fundo Europeu de Desenvolvimento Regional” (FEDER). P. Martins, R. Gonçalves, D. M. Correia and V. Sencadas acknowledges also support from FCT (SFRH/BPD/96227/2013, SFRH/BD/88397/2012, SFRH/BD/90215/2012, SFRH/BPD/64958/2009 grants respectively).

\section{Notes and references}

${ }^{a}$ Centro/Departamento de Física, Universidade do Minho, 4710-057 Braga, Portugal.

*Corresponding author: pmartins@fisica.uminho.pt; lanceros@fisica.uminho.pt

${ }^{b}$ Centro/Departamento de Química, Universidade do Minho, 4710-057 Braga, Portugal.

${ }^{c}$ Departamento de Química Física, Facultad de Ciencia y Tecnología, Universidad del País Vasco/EHU, Apdo.644, Bilbao E-48080, Spain
${ }^{d}$ Basque Center for Materials, Applications and Nanostructures (BCMaterials), Parque Tecnológico de Bizkaia, Ed. 500, Derio 48160, Spain

1. P. Martins and S. Lanceros-Méndez, Adv. Funct. Mater., 2013, 23, 3371-3385.

2. A. Maceiras, P. Martins, R. Gonçalves, G. Botelho, E. Venkata Ramana, S. K. Mendiratta, M. San Sebastián, J. L. Vilas, S. Lanceros-Mendez and L. M. León, Eur. Polym. J., 2015, 64, 224-228.

3. J. Jin, F. Zhao, K. Han, M. A. Haque, L. Dong and Q. Wang, Adv. Funct. Mater., 2014, 24, 1067-1073.

4. W. Eerenstein, N. D. Mathur and J. F. Scott, Nature, 2006, 442, 759765.

5. R. Gupta, M. Tomar, V. Gupta, Y. Zhou, A. Bhalla and S. Priya, Adv. Sci. Lett., 2014, 20, 1116-1119.

6. P. Gupta and P. Poddar, RSC Advances, 2015, 5, 10094-10101.

7. A. Baji, Y. W. Mai, R. Yimnirun and S. Unruan, RSC Advances, 2014, 4, 55217-55223.

8. N. A. Spaldin and M. Fiebig, Science, 2005, 309, 391-392.

9. K. Chand Verma, S. K. Tripathi and R. K. Kotnala, RSC Advances, 2014, 4, 60234-60242.

10. M. Fiebig, J. Phys. D: Appl. Phys., 2005, 38, R123-R152.

11. P. Martins, C. M. Costa, J. C. C. Ferreira and S. Lanceros-Mendez, J. Phys. Chem. B, 2012, 116, 794-801.

12. A. Chaudhuri and K. Mandal, J. Magn. Magn. Mater., 2015, 377, 441-445.

13. J. Otaigbe, M. Barnes, K. Fukui, B. Sumpter and D. Noid, in Polymer Physics and Engineering, Springer Berlin Heidelberg, 2001, vol. 154, pp. 1-86.

14. K. Yue, R. Guduru, J. Hong, P. Liang, M. Nair and S. Khizroev, PLoS ONE, 2012, 7, 44040.

15. C. Luo, T. Okubo, M. Nangrejo and M. Edirisinghe, Polym. Int., 2015, 64, 183-187.

16. Y. Cao, B. Wang, Y. Wang and D. Lou, RSC Advances, 2014, 4, 30430-30439.

17. H. B. Kang, C. S. Han, J. C. Pyun, W. H. Ryu, C. Y. Kang and Y. S. Cho, Compos. Sci. Technol., 2015, 111, 1-8.

18. S. Banerjee, D. Konwar and A. Kumar, Sens Actuat B-Chem, 2014, 190, 199-207.

19. Y.-H. Lee, F. Mei, M.-Y. Bai, S. Zhao and D.-R. Chen, J. Control. Release, 2010, 145, 58-65.

20. L. Konermann, R. G. McAllister and H. Metwally, J. Phys. Chem. B, 2014, 118, 12025-12033.

21. D. M. Correia, R. Gonçalves, C. Ribeiro, V. Sencadas, G. Botelho, J. L. G. Ribelles and S. Lanceros-Méndez, RSC Adv., 2014, 4, 33013-33021.

22. P. Martins, A. C. Lopes and S. Lanceros-Mendez, Prog. Polym. Sci., 2014, 39, 683-706.

23. R. Gonçalves, P. M. Martins, C. Caparrós, P. Martins, M. Benelmekki, G. Botelho, S. Lanceros-Mendez, A. Lasheras, J. Gutiérrez and J. M. Barandiarán, J. Non-Cryst. Solids, 2013, 361, 93-99.

24. T. Wu, B. Zhou, T. Zhu, J. Shi, Z. Xu, C. Hu and J. Wang, RSC Advances, 2015, 5, 7880-7889. 
25. K. Khaja Mohaideen and P. A. Joy, J. Magn. Magn. Mater., 2013, 346, 96-102.

26. J. Wang, Z. Zhou, L. Wang, J. Wei, H. Yang, S. Yang and J. Zhao, RSC Advances, 2015, 5, 7349-7355.

27. S. Amiri and H. Shokrollahi, Mater. Sci. Eng. :C, 2013, 33, 1-8.

28. L. L. Sun, B. Li, Z. G. Zhang and W. H. Zhong, Eur. Polym. J., 2010, 46, 2112-2119.

29. W. Lin, Y. Miao, H. Zhang, B. Liu, Y. Liu, B. Song and J. Wu, J. Lightwave Technol., 2013, 31, 2599-2605.

30. M. F. Valan, A. Manikandan and S. A. Antony, J. Nanosci. Nanotechnol., 2015, 15, 4543-4551.

31. P. Martins, A. Lasheras, J. Gutierrez, J. M. Barandiaran, I. Orue and S. Lanceros-Mendez, J. Phys. D: Appl. Phys., 2011, 44, 495303.

32. X. Chen, S. Wei, C. Gunesoglu, J. Zhu, C. S. Southworth, L. Sun, A. B. Karki, D. P. Young and Z. Guo, Macromol. Chem. Phys., 2010, 211, 1775-1783.

33. J. Gomes, J. S. Nunes, V. Sencadas and S. Lanceros-Mendez, Smart Mater. Struct., 2010, 19

34. P. Martins, C. M. Costa, M. Benelmekki, G. Botelho and S. Lanceros-Mendez, Crystengcomm, 2012, 14, 2807-2811.

35. C. Merlini, G. M. O. Barra, T. Medeiros Araujo and A. Pegoretti, RSC Adv., 2014, 4, 15749-15758.

36. R. Belouadah, D. Guyomar, B. Guiffard and J.-W. Zhang, Physica B, 2011, 406, 2821-2826.

37. G. Botelho, S. Lanceros-Mendez, A. M. Gonçalves, V. Sencadas and J. G. Rocha, J. Non-Cryst. Solids, 2008, 354, 72-78.

38. L. Fang, W. Wu, X. Huang, J. He and P. Jiang, Compos. Sci. Technol., 2015, 107, 67-74.

39. S. Zulfiqar, M. Rizvi and A. Munir, Polym. Degrad. Stabil., 1994, 46, 19-23.

40. M. P. Silva, V. Sencadas, G. Botelho, A. V. Machado, A. G. Rolo, J. G. Rocha and S. Lanceros-Mendez, Mater. Chem. Phys., 2010, 122, 87-92.

41. M. L. O'Shea, C. Morterra and M. J. D. Low, Mater. Chem. Phys., 1990, 26, 193-209.

42. K. Mitsuda, H. Kimura and T. Murahashi, J Mater Sci, 1989, 24, 413-419.

43. P. Martins, C. M. Costa, M. Benelmekki, G. Botelho and S. Lanceros-Méndez, J Mater Sci, 2013, 48, 2681-2689.

44. M. Vopsaroiu, M. Stewart, T. Hegarty, A. Muniz-Piniella, N. McCartney, M. Cain and G. Srinivasan, Meas. Sci. Technol., 2008, 19

45. S. H. Xie, Y. Y. Liu and J. Y. Li, Front. Phys., 2012, 7, 399-407.

46. J. M. Rondinelli, M. Stengel and N. A. Spaldin, Nat. Nanotechnol., 2008, 3, 46-50.

\section{Table of Contents Graphic}

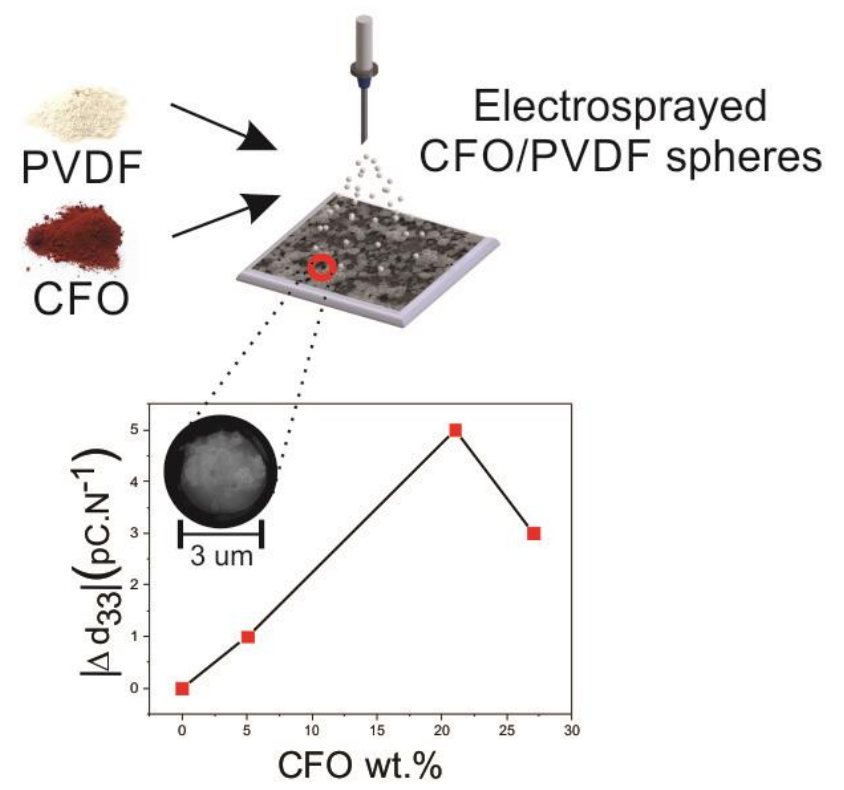

